\title{
Acquisition of consultative status under the Antarctic Treaty
} Serge Pannatier

Faculty of Law and Economics, University of Neuchâtel, Avenue du Premier-Mars 26, 2000 Neuchâtel, Switzerland

Received July 1993

ABSTRACT. Under the regime established by the Antarctic Treaty of 1959, decision-making remains exclusively with the limited number of states that are entitled to appoint representatives to participate in Antarctic Treaty Consultative Meetings. Whereas the 12 original signatory states have a permanent right to attend these meetings, acceding states may gain consultative status only during the time they carry out substantial scientific research in the Antarctic. This paper addresses three issues: the first relates to the problems arising out of the 'admission procedure' adopted by the original signatory states when faced with the first application of an acceding state to become an Antarctic Treaty Consultative Party, a procedure that has been applied ever since to similar cases. The second looks at the forms of scientific research activities an acceding party ought to conduct in Antarctica in order to meet the requirements laid down in the Antarctic Treaty. The third deals more generally with the issue of limited participation in the Antarctic Treaty decision-making process, which has come under severe criticism from non-Consultative Parties and states that have not acceded to the Treaty.

\section{Contents}

Introduction

Admission procedure to consultative status

Criteria for consultative status

Problems related to limited participation

Conclusions

Acknowledgements

References
123

123

126

127

129

129

129

\section{Introduction}

One of the most significant features of the Antarctic Treaty of 1959 is Article IX, which provides for the holding of periodic meetings between the representatives of the contracting parties. This provision has turned out to be of crucial importance: it has created the framework of the successful intergovernmental cooperation that has been taking place in Antarctica for more than 30 years. These meetings have been referred to as Antarctic Treaty Consultative Meetings (ATCMs), a term that appears in Rule 1 of the Rules of Procedure adopted at the first meeting in 1961 (Heap 1990: D1). The lack of formality that characterises this provision is due to the opposition of claimant states, such as Argentina, Australia, and Chile, which strongly resisted any form of international organisation, because this could be interpreted as a sign of the internationalisation of Antarctica. It has been criticised on the ground that such an informal structure is 'inadequate to deal with numerous issues and detailed drafting' (Auburn 1982: 154). This criticism appears totally unjustified in the light of the astonishing evolution of the legal regime drawn up for Antarctica (Quigg 1983: 150; Sahurie 1992: 111-112).

At these meetings, the participating states exchange information; consult on matters of common interest pertaining to Antarctica; and formulate, consider, and recommend to their governments measures in furtherance of the principles and objectives of the Treaty (Article IX.1). An Antarctic Treaty Consultative Meeting can therefore be compared to 'an institution of limited membership exercising important functions which are central to the work of the organisation' (Watts 1992: 14). A state that wishes to be involved in Antarctic affairs will logically seek admission to this forum. The recent Protocol on Environmental Protection to the Antarctic Treaty (ATCPs 1992: Articles 10,11, 12, and 17) confers additional functions on the ATCMs.

\section{Admission procedure to consultative status}

Access to ATCMs was originally limited to Antarctic Treaty Consultative Parties (ATCPs), a term defining the two categories of states that take part in the decisionmaking process. On one hand, the 12 original signatory states to the Antarctic Treaty have a permanent right to attend the meetings, no matter what they do or do not do. On the other hand, states that have acceded to the Treaty according to Article XIII 'shall be entitled to appoint representatives to participate in the meetings referred to in paragraph 1 of the present Article, during such times as that Contracting Party demonstrates its interest in Antarctica by conducting substantial research activity there' (Article IX.2). Unlike the signatory states, these states in theory retain consultative status only if they continue to demonstrate a special interest in Antarctica. Acceding states that do not fulfil this condition are known as 'non-Consultative Parties' (NCPs), and did not participate at all in ATCMs until 1983. At that time, due to the steady increase in the number of NCPs and to their wishes to be more closely associated with the activities of the ATCMs than they had been in the past, the Consultative Parties decided to invite them to attend the next meeting. The Rules of Procedure were amended to allow for their participation (Heap 1990: D2). Two years later, Recommendation XIII-15 was passed and put the matter on a permanent basis: the NCPs were invited not only to the next ATCM and its Preparatory Meeting but to 'all future regular Consultative Meetings, and their Preparatory Meetings' (Heap 1990: 1109). The NCPs are not mere observers, but they are not entilled to participate in the taking of decisions (Rules 26-29 of the Rules of Procedure for ATCMs 1961, revised in 1983, 1987, and 1992).

Since the Antarctic Treaty came into force in 1961, 30 states have acceded to it, half of them later becoming 
ATCPs. Allowing for the merger of the German Democratic Republic with the Federal Republic of Germany in 1990, there are 26 Consultative Parties and 15 NCPs (Fig. 1).

Oddly enough, the Antarctic Treaty is silent on the question of the procedure by which acceding states may obtain consultative status. It only submits it to the demonstration of a 'substantial scientific interest' in Antarctica. It does not say who determines whether an applicant state has complied with this requirement nor what the criteria are for establishing 'substantial scientific interest.'

A literal interpretation of Article IX.2 may suggest, as some authors have pointed out (Roberts 1978: 117; Aubum 1982: 148), that, once an acceding state has fulfilled the 'substantial scientific interest' condition, it has an automatic right to claim a seat at the next ATCM. This view cannot, however, be logically sustained. Sahurie (1992: 114) has observed that 'it is unrealistic to pretend that the consultative parties would allow others to participate in ATCMs unless they themselves agree to it.' Therefore, the problem consists in filling up the loophole that affects Article IX.2 of the Antarctic Treaty. Watts has summarised the issue: 'It would be inappropriate to allow a prospective Consultative Party to assess for itself the adequacy of its own Antarctic activities and then, having decided favourably, just turn up as of right to the next Consultative Meeting; but it would be equally inappropriate for the Consultative Parties to establish an "admission" procedure which might derogate from a right conferred by the Treaty' (Watts 1992: 15).

It was not until 1977 that the ATCPs were faced with the first notification of an acceding state - Poland seeking consultative status. A Special Antarctic Treaty Consultative Meeting was convened to deal with the issue, and a procedure to apply in similar circumstances was adopted. According to the rules established, a state that considers itself to be entitled to take part in ATCMs is to notify the Depository (the government of the United States) of its intention and to provide the information related to its activities in the Antarctic, in particular the content and objectives of its scientific programmes. This notification and the information attached to it are then circulated among and evaluated by the Consultative Parties. Within 12 months of this communication by the Depository, the government in charge of hosting the next ATCM convenes a Special Antarctic Treaty Consultative Meeting to determine 'whether to acknowledge that the acceding State in question has met the requirements of Article IX, paragraph 2 of the Antarctic Treaty' (ATCPs 1978). This acknowledgement is subject to the agreement of all Consultative Parties; the applicant state is then notified by the government that hosted the special meeting.

To qualify for consultative status, an acceding state must observe the principles and purposes of the Antarctic Treaty. The Consultative Parties base this requirement on Article X, which provides that no one should engage in any activity in Antarctica contrary to the principles or purposes of the Treaty. This means, if one accepts the opinion that the recommendations adopted at ATCMs are included among the principles and objectives of the Treaty, that the Consultative Parties may urge the applicant state to approve those measures before it is acknowledged to have fulfilled the prescribed conditions (Bush 1982: 336). So far, each application for consultative status contained a declaration in which the applicant state declared its intention to approve all recommendations previously adopted.

Noting that Poland had established a permanent scientific station, had approved all the recommendations adopted at previous meetings, and was conducting research in Antarctica in accordance with Article IX.2 of the Treaty, the Consultative Parties acknowledged that Poland had the right to appoint representatives in order to participate in ATCMs (ATCPs 1978). Following the same procedure, 14 additional acceding states have become Consultative Parties: the Federal Republic of Germany (1981); Brazil and India (1983); China and Uruguay (1985); the German Democratic Republic and Italy (1987); Spain and Sweden (1988); Peru, the Republic of Korea, and Finland (1989); and Ecuador and the Netherlands (1990) (Fig. 1).

Under the procedure adopted in 1977, access to ATCMs depends on the unanimous agreement of the Consultative Parties. In 1989, faced with the notifications of and information received from the governments of Ecuador and the Netherlands, the Consultative Parties could not reach a consensus on whether to acknowledge that these two states had complied with the prescribed requirements (ATCPs 1990a). This meant that Ecuador and the Netherlands could not appoint a voting delegate to the Fifteenth ATCM, which was held in Paris in October 1989. This situation was reversed a year later when these two states became Consultative Parties (ATCPs 1991).

This example reveals that, although the procedure adopted in July 1977 suggests that achieving consultative status is acknowledged and not granted, the Consultative Parties decide, case by case, on whether to admit an acceding state into their 'club.' One point of view is that it 'is highly doubtful if this procedure is legally in accordance with the terms of the Treaty' (Bos 1989: 102).

At the Fourteenth ATCM, in October 1987, the Consultative Parties agreed with a proposal of the United States delegation, which suggested that guidelines be elaborated for the information that is to be submitted in support of a notification seeking acknowledgement for consultative status. According to these guidelines, which in no way affect the provisions of Article IX or any party's right to interpret those provisions, an applicant state is expected to provide:

1. a complete description of its past scientific programmes and activities in Antarctica, including published results or studies;

2. a complete description of its ongoing and planned scientific programmes and activities in Antarctica, including how they relate to long-term scientific objectives; and

3. a complete description of the planning, manage- 
Fig. 1. Contracting Parties to the Antarctic Treaty.

Original Signatory Parties
United Kingdom
South Africa
Belgium
Japan
United States of America
Norway
France
New Zealand
USSR
(Russia since December 1991)
Argentina
Australia
Chile

\section{Acceding Consultative Parties}

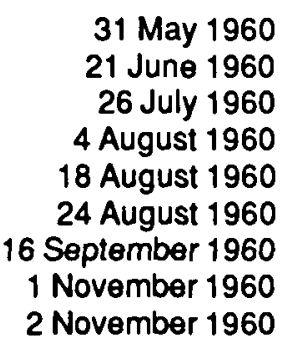

23 June 1961

23 June 1961

23 June 1961

Date of accession

Poland

Netherlands

German Democratic Republic

Brazil

Federal Republic of Germany

Uruguay

italy

Peru

Spain

China (People's Republic)

India

Sweden

Finland

Korea (Seoul)

Ecuador
8 June 1961

30 March 1967

19 November 1974

16 May 1975

5 February 1979

11 January 1980

18 March 1981

10 April 1981

31 March 1982

8 June 1983

19 August 1983

24 April 1984

15 May 1984

28 November 1986

15 September 1987 ment, and execution of its scientific programmes and activities in Antarctica, including identification of the governmental and non-governmental institutions involved (ATCPs 1988).

Once the Protocol on Environmental Protection to the Antarctic Treaty has entered into force, a new condition will have to be complied with by a state seeking for consultative status. The Protocol's Article 22.4 requires that a state, to be acknowledged as a Consultative Party, must first have ratified, accepted, approved, or acceded to the Protocol, which is regarded as an integral part of the Antarctic Treaty.

In case of a dispute concerning the fulfilment of the requirements to be met by an applicant state, it would probably be referred to the disputes settlement procedure of Article XI of the Antarctic Treaty (Bush 1982: 334).

$A$ question that does not receive any definite answer relates to the legal nature of the decision by which the Consultative Parties welcome a new member in their group. If it is constitutive, it means that the acceding state becomes a Consultative Party on the date the decision has been adopted; if, on the contrary, it only confirms an existing state of affairs, the same state has become a Consultative Party on the day it has established its station or it has dispatched a scientific expedition to Antarctica.

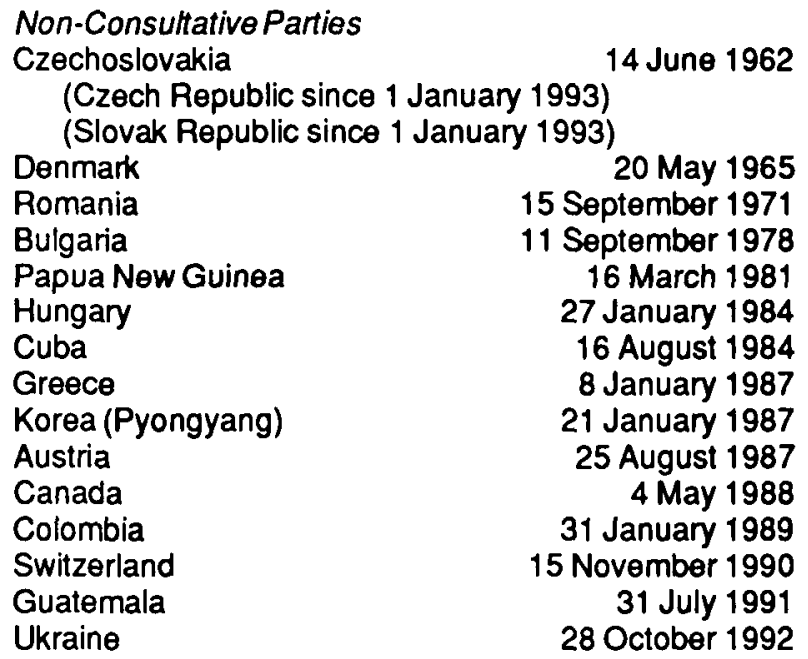

$$
\begin{array}{r}
\text { Date consultative } \\
\text { status achieved } \\
29 \text { July } 1977 \\
19 \text { November } 1990 \\
5 \text { October } 1987 \\
12 \text { September } 1983 \\
3 \text { March } 1981 \\
7 \text { October } 1985 \\
5 \text { October } 1987 \\
9 \text { October } 1989 \\
21 \text { September } 1988 \\
7 \text { October } 1985 \\
12 \text { September } 1983 \\
21 \text { September } 1988 \\
9 \text { October } 1989 \\
9 \text { October } 1989 \\
19 \text { November } 1990
\end{array}
$$

The wording of the existing decisions leaves it open to argue in favour of either solution. The practice, however, has shown that acceding states have always become Consultative Parties on the day their applications have been accepted.

The measures decided at Consultative Meetings have been traditionally referred toas 'Recommendations.' They become effective only after they have gone through an approval procedure of double unanimity. They must first be approved by all present-and-voting delegates at the Consultative Meeting and then by the government of each Consultative Party (Antarctic Treaty: Article IX.4). Ratification by governments usually takes time, so the effectiveness of a measure is often delayed. The decision related to the admission of a new Consultative Party does not, however, follow the same procedure. Citing the United States delegation's report of 24 August 1977 , concerning the case of Poland, Auburn indicated (1979: 516) that 'The final report of July 1977 was regarded as having immediate legal effect.' As such a procedure is not directly sanctioned by the Antarctic Treaty, it can logically be concluded that the Parties' delegates have been empowered by their governments to provide the approval required by Article IX.4. 


\section{Criteria for consultative status}

To participate in Consultative Meetings, an acceding state must demonstrate its interest in Antarctica 'by conducting substantial scientific research activity there' (Antarctic Treaty: Article IX.2). The interpretation of this criterion again creates problems. The Antarctic Treaty does not contain any definition of what form the scientific activity must take. It only says it must be 'substantial' and then gives two examples of such activity, the establishment of a scientific station or the dispatch of a scientific expedition. But Auburn has pointed out (1982: 152) that 'it is not clear how "substantial" the research must be.' The many questions arising out of the vague wording of Article IX have been considered in detail by Bush (1982: 334-336). But to give an overview of the practice followed by the Consultative Parties in 'acknowledging' that a country has complied with the requirements laid down in Article IX.2 of the Antarctic Treaty appears to be useful.

The admission of new Consultative Parties

For a long time, the effective practice related to the admission of new Consultative Parties has been to require the establishment of a permanent station in Antarctica (Sahurie 1992: 117). Joint expeditions organised by various states have not been considered as sufficient evidence of interest. Such practice has resulted in maintaining a rather small number of Consultative Parties. To set up a scientific station in Antarctica constitutes a heavy cost for a developing country. According to Aubum (1982: 152), "Not only is the high entry fee of "substantial scientific research" a hindrance to seeking status, but it is also a disincentive to any such nation even acceding to the Treaty when it can have no say in decision-making.' It must, however, be mentioned that only in the cases of Ecuador and the Netherlands have the Consultative Parties not been able to reach a consensus on whether states had satisfied the prescribed requirements (ATCPs 1990a). And only a year after, the situation was altered and the two states concerned were able to appoint delegates to vote at Consultative Meetings (ATCPs 1991).

Political reasons have played an important role in the decision to admit new members as Consultative Parties. 'Increasing demands about the more immediate economic value of Antarctica have prompted demands for radical changes in Antarctic processes to share in the riches' (Sahurie 1992: 576). These demands, originating from the countries belonging to the 'Non-Aligned Movement,' have been included on the agenda of the United Nations General Assembly since 1983. Since that year, the 'Question of Antarctica' has been debated every year by the General Assembly, and several resolutions on the topic have been adopted despite the non-participation in the vote of a number of Antarctic states (Beck 1993: 313-320). The main criticism has related to participation in the Antarctic Treaty System. It has relied on the argument that Antarctica forms part of the common heritage of mankind and that the limited number of states that rule it is not representative of the international community.
Such criticism explains why the stringency of the requirements for admission to consultative status has been softened in some cases. Brazil and India, for example, are two influential third-world countries. They have been welcome to take part in ATCMs even if they did not have scientific stations at the time when their notifications for consultative status were considered. The admission of these two states to full competence in decision-making can be seen as the answer of the Consultative Parties to those who have criticised the privileged and exclusive nature of the ATCPs (Beck 1986: 198). India is the only state that has considered itself entitled to consultative status on the very day it acceded to the Antarctic Treaty.

If ascension to consultative status by Brazil and India can be regarded as the response of the Antarctic powers to external criticism of the Treaty regime, the Latin American factor appears to be another political justification for the admission of new states to full decision-making in Antarctic affairs. Using proximity (sector theory) or historical rights (doctrine of uti possidetis) as evidence of their interest in Antarctica, Uruguay, Peru, and Ecuador have sought and achieved consultative status between 1985 (Uruguay) and 1990 (Ecuador). Due to the scarcity of financial and technical means, the contribution of these states to Antarctic science remains modest. But, as was pointed out by Joyner and Ewing Jr (1991: 3):

Latin American geopolitics is built upon future possibilities. This tendency to set present policy based on future expectations is clearly seen in Latin American States' attitudes toward potential Antarctic resources, both minerals and living marine, and the premise that technological advances will someday permit exploitation of those resources. Until that day arrives, the need exists to preclude other States from intruding on or interfering in Antarctic territory and access to resources.

In order to fulfil the 'substantial scientific interest' criterion contained in the Antarctic Treaty (Article IX.2), each one of these three states established a base in the Antarctic. Backed up by Argentina and Chile, their applications for access to the decision-making process were accepted, although the quality of their scientific programmes remains questionable. 'Crudely put, one might say that politicians do not need to worry so much about the kind of work their scientists do, as long as they are there in Antarctica and one can show that a "significant performance of research" is going on' (Elzinga and Bohlin 1993: 22).

The case of Ecuador reflects the weight of the Latin American factor. Ecuador acceded to the Antarctic Treaty on 15 September 1987. In 1989, when it first applied for consultative status, there was no consensus among the Consultative Parties that the scientific activities have fully met the requirements of Article IX, paragraph 2 of the Antarctic Treaty' (ATCPs 1990a). Six months later, on 2 March 1990, a scientific station named 'Pedro Maldonado' was established by an Equatorian expedition on Greenwich Island, South Shetland Islands, and the following 
November, Ecuador was welcomed among the Consultative Parties (ATCPs 1991).

The requirement of a permanent station has unfortunately resulted in an undesirable consequence: the few Antarctic areas of easy access (mainly the South Shetland Islands) are now overcrowded with stations. Such a concentration of human activities is likely to affect the environment and gives rise to questions of scientific productivity and the need for cooperation (Heap 1990: 2111-2113).

This issue has been dealt with on several occasions by the Consultative Parties. In Recommendation XIII-6, they recommended to their governments 'that where stations have been established in the same vicinity the concerned national Antarctic operating agencies should consult together, by whatever means found appropriate, so as to safeguard existing scientific activities, avoid operational logistic difficulties and avoid undue adverse environmental effects arising from cumulative impacts' (ATCPs 1986).

During the Fourteenth ATCM, although no recommendation was adopted on the subject, the discussion focused on three aspects of the matter. First, the Consultative Parties agreed, in order to increase the opportunities for contributing to scientific knowledge, that 'new stations should be so situated as to maximize their scientific potential and should not be situated in locations which devalue the programmes of existing stations.' Second, it was suggested that consultation before, rather than after, the station is established would be preferable. Third, a proposal was made to create a new category of protected areas in connection with land-use planning around existing stations (ATCPs 1988).

At the next Consultative Meeting, which was held in Paris in 1989, Recommendation XV-17 was adopted (ATCPs 1990b). Summarising the discussion of the previous meeting, it urged that parties considering the establishment of a new station prepare a comprehensive environmental evaluation as defined in Recommendation XIV2 (ATCPs 1988). Multiple-Use Planning Areas (MPAs) have also been created in order to coordinate the management of human activities in those areas where they pose identified risks of mutual interference or cumulative environmental impacts (ATCPs 1990b: Recommendation XV11). In 1991 the Protocol on Environmental Protection to the Antarctic Treaty generalised the obligation of assessing the environmental impacts of all human activities in Antarctica (Article 8) and its Annex I set out the procedure in great detail.

In 1990 the Netherlands became a Consultative Party although it had not established and did not plan to establish a station in Antarctica. Its scientists have, however, undertaken a wide variety of scientific studies in various parts of the Antarctic, either on their own or in cooperation with expeditions of other nations, since the accession of their country to the Antarctic Treaty. Moreover, the Netherlands has developed a programme of environmental impact studies on King George Island, for which purpose it was planned to rent a large part of Poland's
Arctowski station (ATCPs 1991).

The new interpretation of the 'substantial scientific interest' criterion opens promising perspectives for the future. From now on it may well not be enough to build a small station on King George Island and to declare that scientific research is conducted there in order to attain the right to participate in Consultative Meetings: 'it seems possible that the ATCPs may be tempted to reinterpret the "substantial scientific activity" clause in Article IX of the Antarctic Treaty, in order to remove an "artificial stimulus" for the construction of additional permanent facilities in Antarctica, with attendant damage done to the environment' (Joyner and Ewing Jr 1991: 45). This interpretation could also contribute to the improvement of the science that is undertaken in the Antarctic. And it could eventually help to reduce the environmental impacts resulting from the concentration of human activities in easily accessible sites for stations.

\section{Problems related to limited participation}

In a slowly dying debate in front of the United Nations General Assembly (Beck 1993: 313-320), the Antarctic Treaty System (ATS) has been subject to severe criticism coming from states belonging to the Non-Aligned Movement. According to them, the fundamental problem relates to the exclusiveness of the decision-making process. Speaking of the 'rights' of the Consultative Parties, the Malaysian Ambassador, Zain-Azraai, asserts 'that, under the Treaty, the ATCPs - and they alone - have the rights to make decisions ('exclusive'), and that the ATS assert rights to regulate all activities in Antarctica ('total'), and that decisions within the ATS are not subject to review or even discussion by any other body ('unaccountable')' (ZainAzraai 1987: 212). The distinction between Consultative Parties and other Treaty parties has also come under attack from authors writing from the perspective of non-Consultative Parties (Brückner 1986; Caflisch 1992: 160). The latter argues that this distinction, which might have been justified 'when Antarctic activities focused on scientific matters' has become discriminatory, as other matters, such as the preservation of the environment, are gaining importance. 'Why, then, should some states be more equal than others when it comes to establishing an environmental regime for the Antarctic region?' (Caflisch 1992: 160).

To overcome these difficulties, critics have put forward various proposals to increase the representation of the international community in the decision-making process or to replace the actual Treaty System by a universal regime similar to the one established for the sea-bed by the Convention on the Law of the Sea of 1982 (Orrego Vicuna 1988: 479-492).

Most of these critics are unjustified. The Antarctic Treaty is open to any United Nations member or any other state, with the consent of all Consultative Parties for the latter. Today, 41 states representing a great majority of the world population and the main political and economic regimes have ratified the Treaty (Fig.1). Certainly, decision-making remains exclusively within a limited group of 
parties. A system in which parties have different rights and obligations is, however, not new in public international law. As the French international lawyer René-Jean Dupuy (1960: 119; translation by F. Orrego Vicuña) has pointed out: 'This hierarchical system is unusual in that it is based, not on qualitative criteria, but on considerations of quantitative nature: the actual importance of research carried out in the Antarctic. This is what gives the Treaty a character usually found in treaties dealing with technical matters or which set up specialised communities.'

Science has been at the origin of the Antarctic Treaty (Gould 1970: 5-10). Today, it remains the main activity carried out in the Antarctic. Therefore, access to decisionmaking must continue to be restricted to those with direct interest and knowledge of Antarctica (Conforti 1987: 3). It is wrong to claim that the Treaty System protects only the interests of its members. It should not be forgotten that the Consultative Parties also belong to the international community and that they have succeeded in managing Antarctica in the interest of mankind for more than 30 years (Sahurie 1992: 582). By limiting the participation in decision-making to those having a concrete experience of the region, the Consultative Parties have succeeded in establishing a stable political order for Antarctica. Such achievements cannot be ignored, even if they have yet to convince the wider international community of the gains.

\section{Conclusions}

The Antarctic Treaty limits access to decision-making to those states that have a special scientific interest in Antarctica. It does, however, not say who is responsible for determining if an acceding state seeking consultative status has satisfied this requirement. The obscure wording of the Antarctic Treaty on this matter, if it has proved to be politically advantageous, allowing for pragmatic and policy considerations, creates legal problems. It has given rise to conflicting interpretations on whether or not an acceding state automatically becomes a Consultative Party when it has fulfilled the condition. The only way to solve this juridicial problem would be to amend Article IX.2 of the Antarctic Treaty. Such a procedure is very unlikely to happen due to the fact that no state is ready to threaten the future of the Antarctic regime by calling for a review conference.

Existing Consultative Parties have been wise enough not to opt for either one or the other interpretation: they do not 'grant' consultative status but they simply 'acknowledge' that an applicant state has met the prescribed requirements. In practice, however, decisions have been made case by case depending on the influence of the prospective Consultative Party. An examination of the scientific merits of the programmes put forward by acceding Consultative Parties clearly demonstrates that the level of research undertaken by the first two applicants was significantly higher than that carried out by subsequent applicants, such as Brazil, India, China, Uruguay, or Ecuador. However, the admission of leading third-world countries to decision-making has been a means to undermine the criticism related to the exclusiveness of the Antarctic Treaty System originating in the Non-Aligned Movement and amplified, since 1983, by a yearly debate at the United Nations General Assembly.

Until 1990, a state seeking consultative status had to establish a permanent scientific station in Antarctica and to declare that it would abide by the principles of the Treaty in order to satisfy the criteria for admission. Such policy unfortunately resulted in the congestion of easily accessible sites for stations. The recent concern for the protection of the Antarctic environment, which has materialised in the Protocol on Environmental Protection to the Antarctic Treaty, is likely to affect the issue. Since the admission of the Netherlands in 1990, it is not necessary to set up a permanent station to meet the requirements laid down in the Antarctic Treaty. This must be seen as an important precedent. Not only does it demonstrate the concern of the Consultative Parties for the protection of the environment, but it should also improve the quality of scientific programmes carried out in Antarctica. It remains, however, to be seen if the admission policy becomes more restricted in the future than it has been in the recent past.

\section{Acknowledgements}

My major debt of gratitude is to the Swiss National Foundation for Scientific Research (FNRS) whose financial support allowed me to spend six months at the Scott Polar Research Institute of the University of Cambridge. I am also grateful to the Scott Polar Research Institute for accepting me as a Visiting Scholar and to its Director, Dr John A. Heap, for the useful information and comments with which he provided me during my visit in Cambridge.

\section{References}

ATCPs. 1978. Final Report of the First Special Antarctic Treaty Consultative Meeting, London, 25, 27, and 29 July 1977. London: Foreign and Commonwealth Office. ATCPs. 1986. Final Report of the Thirteenth Antarctic Treaty Consultative Meeting, Brussels, 7-18 October 1985. Brussels: Kingdom of Belgium, Ministry of Foreign Affairs, External Trade and Co-operation in Development.

ATCPs. 1988. Final Report of the Fourteenth Antarctic Treaty Consullative Meeting, Rio de Janeiro, 5-16 October 1987. Rio de Janeiro: Federative Republic of Brazil, Ministry of External Relations.

ATCPs. 1990a. Final Report of the Ninth Special Antarctic Treaty Consultative Meeting, Paris, 9 October 1989. Paris: Republic of France.

ATCPs. 1990b. Final Repon of the Fifteenth Antarctic Treaty Consultative Meeting, Paris, 9-20October 1989. Paris: Republic of France.

ATCPs. 1991. Final Report of the Tenth Special Antarctic Treaty Consultative Meeting, Viña del Mar, 19 Novem. ber 1990. Santiago: Republic of Chile.

ATCPs. 1992. Protocol on Environmental Protection to the Antarctic Treaty-Final Report of the Eleventh Antarctic Treaty Special Consultative Meeting, Madrid, 22-30 April 1991; 17-22 June 1991; 3-4 October 1991. Madrid: Ministerio de Asuntos Exteriores.

Auburn, F.M. 1979. Consultative status under the Antarctic Treaty. International and Comparative Law Quarterly 
28: 514-522.

Auburn, F.M. 1982. Antarcticlawandpolitics. London: Hurst. Beck, P.J. 1986. The intemational politics of Antarctica. London and Sydney: Croom Helm.

Beck, P.J. 1993. The United Nations and Antarctica, 1992: still searching for that elusive convergence of view. Polar Record 29 (171): 313-320.

Bos, A. 1989. New developments in the Antarctic Treaty System, increased number of parties. Circumpolar Journal 4 (2-3): 100-115.

Brückner, P. 1986. The Antarctic Treaty System from the perspective of a non-Consultative Party to the Antarctic Treaty. In: US Polar Research Board. Antarctic Treaty System: an assessment. Washington DC: National Academy Press: $315-335$.

Bush, W.M. 1982. Antarctica and international law: a collection of inter-state and national documents. Volume I. New York: Oceana Publications.

Caflisch, L. 1992. The interaction between science and politics in the field of international relations: the case of Antarctica. Polar Record 28 (165): 159-162.

Conforti, B. 1987. Introduction. In: Francioni F., and T. Scovazzi (editors). International law for Antarctica. Milan: Giufrè: $1-3$.

Dupuy, R.-J. 1960. Le traité sur l'Antarctique. Annuaire français de droit international 111-132.

Elzinga, A., and I. Bohlin. 1993. The politics of science in polar regions. In: Elzinga, A. (editor). Changing trends in Antarctic research. Dordrecht, Boston, London: Kluwer Academic Publishers: 7-27.
Gould, L.M. 1970. Emergence of Antarctica: the mythical land. Bulletin of the Atomic Scientists 12: 5-10.

Heap, J.A. (editor). 1990. Handbook of the Antarctic Treaty System. Seventh edition. Cambridge: Polar Publications.

Joyner, C.C., and B.C. Ewing Jr. 1991. Antarctica and the Latin American states: the interplay of law, geopolitics and environmental priorities. Georgetown International Environmental Law Review 4 (1): 1-46.

Orrego Vicuna, F. 1988. Antarctic mineral exploitation: the emerging legal framework. Cambridge: Cambridge University Press.

Quigg, P.W. 1983. A pole apart: the emerging issue of Antarctica. New York: McGraw-Hill.

Roberts, B.B. 1978. International co-operation for Antarctic development: the test for the Antarctic Treaty. Polar Record 19 (119): 107-120.

Sahurie, E.J. 1992. The international law of Antarctica. New Haven: New Haven Press.

Watts, A. 1992. International law and the Antarctic Treaty System. Cambridge: Grotius Publications.

Zain-Azraai. 1987. Antarctica: the claims of 'expertise' versus 'interest'. In: Triggs, G.D. (editor). The Antarctic Treaty regime: law, environment and resources. Cambridge: Cambridge University Press.

The accuracy of references in the text and in this list is the responsibility of the author, to whom queries should be addressed. 